\title{
Tiered approach: from plan into practice
}

..industry can and should take responsibility and ownership to define good bioanalytical quality in earlier stages of development, we should use the momentum and our experience to help define bioanalysis for future generations."

Bioanalysts around the world share one common goal: to generate high-quality data for valid scientific decision making. For this, and as part of their scientific responsibility, they have always taken initiatives to ensure that quality and science can go hand-in-hand. Including method-development practices; performing some kind of validation or qualification in front of sample analysis; inclusion of independent quality control samples; or, calibration curves mimicking the real samples as closely as possible during study sample analysis, are just a few examples of practices that originate from dayto-day laboratory practices rather than from regulatory request.

Some 25 years ago, in the early 1990s of the last century, industry and regulators connected to capitalize on framing the most common dayto-day practices used in the bioanalytical laboratory into a consensus document describing bioanalytical method validation and sample analysis when using, in essence, chromatographic assays for small molecules or small-molecule radioimmuno assays (RIA) [1]. Legendary words such as "a small step for man, a giant leap for mankind" (Neil Armstrong, 21 July 1969) are appropriate to use when referring to the impact the resulting conference paper had on the worldwide bioanalytical community.

Moving forward, as known by all of us, this conference paper was and still is the basis of any regulated bioanalysis guidance [2,101-103]. Although science and technology have moved on significantly over the last two decades, we still tend to use method-validation paradigms developed with in essence late-stage clinical Phase I (healthy volunteer) studies in mind for an immensely broadened array of assays we need to support in modern day drug development. Not only did we see a complete shift in chromatographic separation technology or hyphenation facilitating sometimes up to 1000 -fold lower achievable LOQs; but also, by including peptides, proteins/antibodies and ADCs, the portfolios of innovator drug companies have changed dramatically requiring diverse bioanalytical platforms beyond chromatographic techniques or simple RIAs, including hybrid assays or multiplexing. In addition, bioanalysis support increased exponentially because of the need or desire to quantify metabolites, biomarkers (or endogenous compounds in general) in a variety of in vivo and in vitro assays at all stages of drug R\&D.

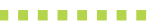 \\ "This special issue of Bioanalysis aims to show some good examples of areas or applications where stepping away from formal validation according to regulatory guidance into different approaches for ensuring scientific valid data ... has proven its merit."}

For biomarkers and metabolite quantification, the industry has already proposed some changes away from regulated validation [3,4]; 'fit-for-purpose' and the 'tiered approach' for metabolite quantification slowly found their way into the bioanalytical laboratory $[5,6]$. But (too) many scientists remain faithful to the guidance principles for a variety of studies where there is no requirement to do so.

This special focus issue of Bioanalysis aims to show some good examples of applications where stepping away from formal validation according to regulatory guidance into different approaches to ensure scientifically valid data, be it fit-for-purpose, the tiered approach, or other formats, has proven its merit. At the same time, it aims at providing a renewed platform for open discussion involving all stakeholders in how our industry can take a fresh look at what is the value of adhering to regulated guidance versus introducing more scientific freedom for bioanalytical studies and application where the guidance may not be required or may prevent

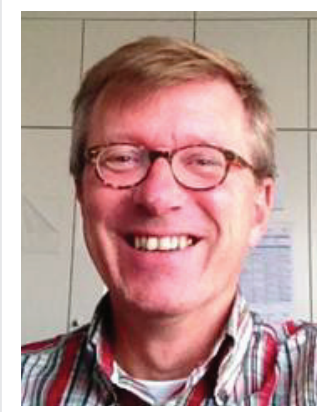

Philip Timmerman

Bioanalysis Department, Janssen R\&D, A Division of Janssen Pharmaceutica NV, Turnhoutseweg 30 ptimmerm@its.jnj.com
FUTURE
SCIENCE 
science from flourishing. Certainly, also considering the recent acknowledgement during the Crystal City-V meeting (Baltimore, MD, USA, 3-5 December 2013) that industry can and should take responsibility and ownership to define good bioanalytical quality in earlier stages of development, we should use the momentum and our experience to help define bioanalysis for future generations.
Financial \& competing interests disclosure The author has no relevant affiliations or financial involvement with any organization or entity with a financial interest in or financial conflict with the subject matter or materials discussed in the manuscript. This includes employment, consultancies, honoraria, stock ownership or options, expert testimony, grants or patents received or pending, or royalties. No writing assistance was utilized in the production of this manuscript.

\section{References}

1 Shah VP, Midha KK, Dighe S et al. Analytical methods validation: bioavailability, bioequivalence, and pharmacokinetic studies. Pharm. Res. 9, 588-592 (1992).

2 Guidance for Industry Bioanalytical Method Validation U.S. Department of Health and Human Services Food and Drug Administration Center for Drug Evaluation and Research (CDER) Center for Veterinary Medicine (CVM) May 2001.

3 Lee J, Devanarayan V, Barrett $Y$ et al. Fit-for-purpose method development and validation for successful biomarker measurement. Pharm. Res. 23(2), 312-328 (2006).
Viswanathan CT, Bansal S, Booth B et al. Workshop/conference report - quantitative bioanalytical methods validation and implementation: best practices for chromatographic and ligand binding assays. AAPS J. 9(1), E30-E42 (2007).

5 Timmerman P, Kall M, Gordon B et al. Best practices in a tiered approach to metabolite quantification: views and recommendations of the European Bioanalysis Forum. Bioanalysis 2(7), 1185-1194 (2010).

6 Booth B. When do you need a validated assay? Bioanalysis 3(24), 2729-2730 (2011).

\section{Websites}

101 EMEA/CHMP/EWP/192217/2009

Guideline on bioanalytical method validation. www.ema.europa.eu/docs/en_GB/ document_library/Scientific_ guideline/2011/08/WC500109686.pdf

102 Japanese guideline. http://bioanalysisforum.jp/images/ T130918I0020.pdf\#zoom $=100$

103 Anvisa guideline. http://bvsms.saude.gov.br/bvs/saudelegis/ anvisa/2012/rdc0027_17_05_2012.pdf 